\title{
DEPÓSITOS QUATERNÁRIOS DA REGIÃO ENTRE MARÍLIA E PRESIDENTE PRUDENTE (SP)
}

\author{
ALETHÉA ERNANDES MARTINS SALLUN ${ }^{1,2}$ \& KENITIRO SUGUIO ${ }^{2,3}$
}

\begin{abstract}
Resumo Depósitos cenozóicos ocorrem extensivamente entre Marília e Presidente Prudente (SP), superpostos a rochas cretácicas do Grupo Bauru e da Formação Serra Geral. Eles se distribuem irregularmente na área de estudo e foram agrupados em depósitos colúvio-eluviais e aluviais segundo critérios sedimentológicos, morfológicos e genéticos. Os depósitos colúvio-eluviais são caracterizados pela predominância de areia e areia argilosa com alta maturidade mineralógica. Os depósitos mais espessos são caracterizados pela predominância de areia fina. Datações por luminescência forneceram idade pleistocênica para os depósitos colúvio-eluviais $(9.000 \pm 1.000$ a $980.000 \pm 100.000$ anos A.P.) e aluviais $(14.000 \pm 2.000$ a $240.000 \pm 30.000$ anos A.P.). Esses depósitos acham-se instalados sobre quatro superfícies peneplanizadas afeiçoadas no Quaternário: I (1.000.000 a 400.000 anos A.P.), II (400.000 a 120.000 anos A.P.), III (120.000 a 10.000 anos A.P.) e IV (10.000 anos A.P. até hoje). Durante o Quaternário ocorreram pulsos de erosão e sedimentação de depósitos coluviais, colúvio-eluviais e aluviais, intercalados com fases de desenvolvimento de solos sobre as rochas cretácicas. Esses eventos poderiam estar relacionados a mudanças paleoclimáticas e/ou atividades neotectônicas, que causaram mudanças nos níveis de base com conseqüentes transformações do relevo.
\end{abstract}

Palavras-chave: Quaternário, depósito colúvio-eluvial, datação por luminescência

\begin{abstract}
QUATERNARY DEPOSITS BETWEEN MARILIA AND PRESIDENTE PRUDENTE (SP) Quaternary deposits occur extensively between Marília and Presidente Prudente (São Paulo State, Brazil), unconformably (with basal concentration of ferricretes and/or stonelines) or transitionally superimposed to Bauru Group and Serra Geral Formation cretaceous rocks. They are irregularly distributed throughout the study area, and have been grouped into colluvio-eluvial and alluvial deposits, according to sedimentological, morphological and genetical criteria. The colluvio-eluvial deposits are characterized by dominance of sands and clayey sands, with high mineralogical maturity. The thickest deposits are characterized by dominance of fine sands. Luminescence datings indicated Pleistocene age for colluvio-eluvial $(9,000 \pm 1,000$ to $980,000 \pm 100,000$ B.P.) and alluvial $(14,000 \pm 2,000$ to $240,000 \pm 30,000$ B.P.) deposits. These deposits have been installed on four peneplained surfaces shaped during the Quaternary: I (1,000,000 to 400,000 B.P.), II (400,000 to 120,000 B.P.), III (120,000 to 10,000 B.P.) and IV (10,000 B.P. until today). During the Quaternary erosion and sedimentation pulses of colluvial, colluvio-eluvial and alluvial deposits occurred, which were intercalated with soil development phases on cretaceous rocks. These events could be related to paleoclimatic changes and/or neotectonic activities, which caused baselevel changes with consequent relief transformations.
\end{abstract}

Keywords: Quaternary, colluvio-eluvial, luminescence dating

INTRODUÇÃO Depósitos quaternários podem ser encontrados em diversos locais no Estado de São Paulo, associados a distintos contextos geológicos. Estes depósitos foram intensamente estudados na porção leste do Estado em regiões continentais (Bigarella \& Mousinho 1965, Massoli 1980, Meis \& Moura 1984, Melo et al. 1994, Riccomini 1995) e litorâneas (Silveira 1950, Freitas 1951, Cruz 1974, Suguio \& Petri 1973, Martin \& Suguio 1975, Giannini 1987, Massad 1994, Souza 1997). Poucos são os estudos de sedimentos continentais em depósitos interiores, excetuando-se os da Depressão Periférica (Melo et al. 1997, Melo et al. 2001). Dentre estes depósitos têm-se aqueles que ocorrem extensamente no oeste paulista, no denominado Planalto Ocidental, onde se destaca o Planalto de Marília (Figura 1).

Este trabalho foi desenvolvido na dissertação de mestrado de Sallun (2003) e visou estudar parte desses depósitos, principalmente sob pontos de vista sedimentológico e estratigráfico, na área situada entre Marília e Presidente Prudente (SP), com detalhe nunca abordado. Os resultados obtidos contribuíram para melhor compreensão desta parte do Estado, ainda tão pouco conhecida em termos de sua evolução geológica quaternária.

Os estudos geológicos, até hoje realizados na área de estudos, enfocam quase somente o Grupo Bauru (Suguio 1973, Suguio 1980, Barcelos 1984, Fernandes 1998, Batezelli 2003). Estratigraficamente os depósitos quaternários do Planalto Ocidental situam-se em sua maior parte sobre as rochas sedimentares do Grupo Bauru, sob forma discordante, formando corpos descontínuos e irregulares. Os depósitos cenozóicos são praticamente ignorados e, quando estudados, tiveram enfoque essencialmente geomorfológico. Recebendo diferentes denominações e interpretações são, em geral, vagamente referidos como solos ou formações superficiais, e os mapeamentos realizados não conduziram ao reconhecimento de unidades geológicas, portanto, necessitam de estudos sedimentológicos, estratigráficos e paleontológicos mais detalhados. Deste modo, as descrições e interpretações muito vagas e/ou desencontradas precisavam ser mais detalhadas, para se tentar elucidar melhor a evolução geológica cenozóica da área de estudo.

CONTEXTO GEOLÓGICO Na área de estudos ocorrem rochas mesozóicas da Bacia do Paraná, representadas pelo Grupo São Bento e Grupo Bauru, recobertas por depósitos cenozóicos.

A Bacia do Paraná (Figura 2), sensu stricto, é uma vasta bacia intracratônica sul-americana, que abrange uma área de cerca de $1.400 .000 \mathrm{~km}^{2}$ estendendo-se pelo Brasil, Paraguai, Uruguai e Argentina (Zalán et al. 1990). Desenvolvida completamente sobre crosta continental, e preenchida por rochas sedimentares e vulcânicas, abriga um registro estratigráfico temporalmente posicionado entre o Neo-Ordoviciano e o Neocretáceo (Zalán et al. 1990, Milani \& Ramos 1998). São reconhecidas seis uni-

1 - Instituto Geológico, Secretaria do Meio Ambiente do Estado de São Paulo, Avenida Miguel Stéfano, 3900, 04301-903, São Paulo, SP, aletheamartins@hotmail.com

2 - Departamento de Geologia Sedimentar e Ambiental, Programa de Pós-graduação em Geologia Sedimentar, Instituto de Geociências, Universidade de São Paulo, Rua do Lago, 562, 05508-080, São Paulo, SP, kenitirosuguio@hotmail.com

3 - Centro de Pós-Graduação, Pesquisa e Extensão (CEPPE), Universidade Guarulhos (UnG), Rua Dr. Nilo Peçanha, 81 (Prédio U - 6o. andar) - 07023-070, Guarulhos, SP 
dades aloestratigráficas de segunda ordem ou supersequências: Rio Ivaí (Caradociano - Landoveriano), Paraná (Lockoviano-
Frasniano), Gondwana I (Westfaliano-Scythiano), Gondwana II (Anisiano-Noriano), Gondwana III (Neojurássico-Berriasiano)

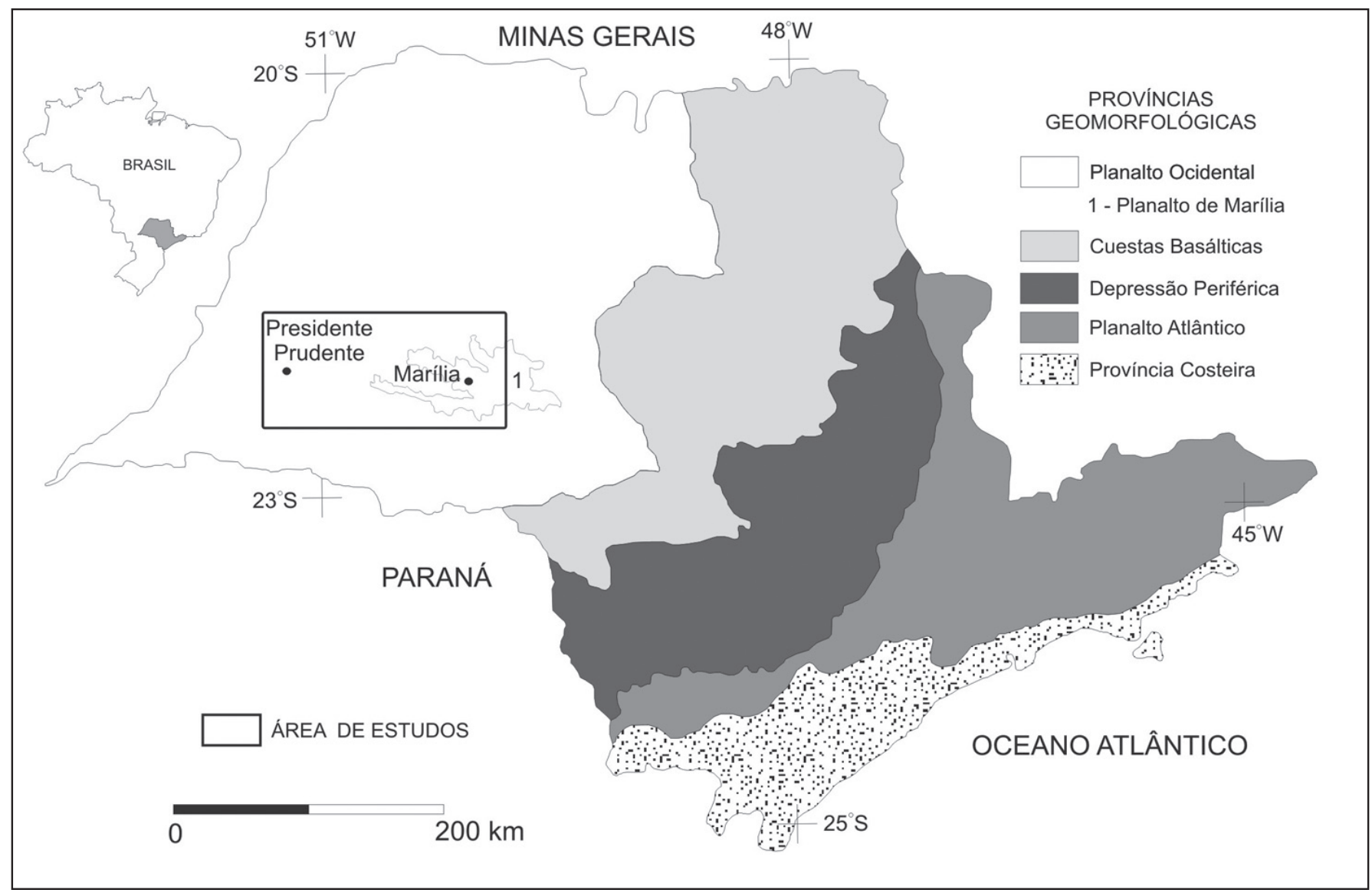

Figura 1 - Situação geográfica da área de estudos e sua localização nas províncias geomorfológicas no Estado de São Paulo, entre

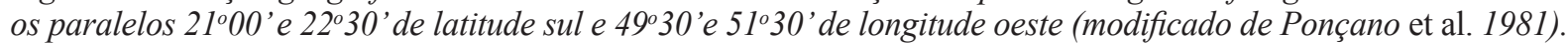

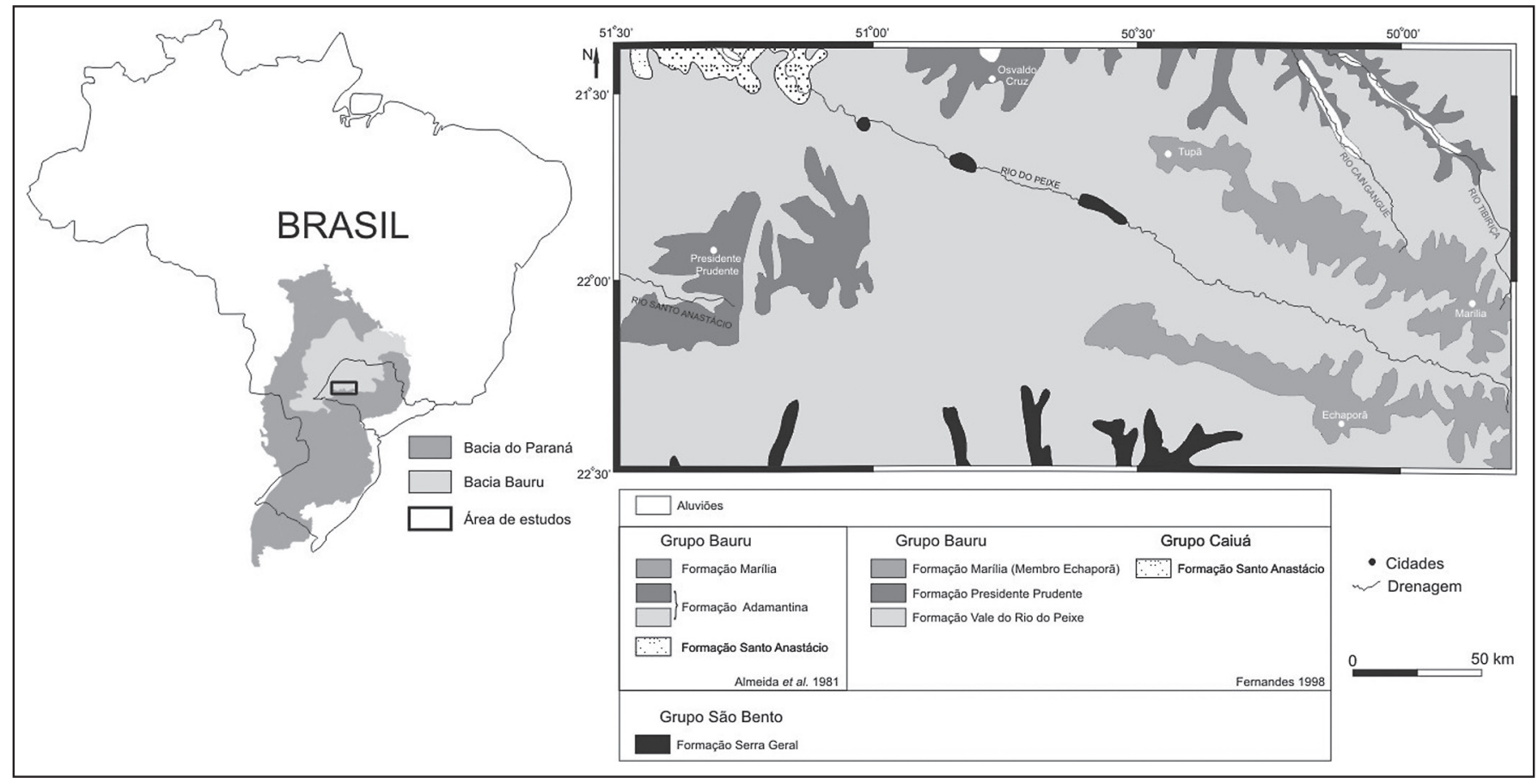

Figura 2 -Localização simplificada da Bacia do Paraná e mapa geológico da área de estudos (modificado de Milani \& Ramos 1998 e Almeida et al. 1981). 
e Bauru (Aptiano-Maestrichtiano) (Milani 1997). A Formação Serra Geral é representada por um conjunto de derrames de basaltos toleíticos de idade em torno de 132,4 1 1,1 Ma (Renne et al. 1992). A Bacia Bauru (Arid 1970, Fúlfaro et al. 1982, Fernandes 1992, Coimbra \& Fernandes 1994, Fernandes \& Coimbra 1996, Fernandes 1998) instalou-se sobre os derrames da Formação Serra Geral.

Segundo Fernandes (1998) a Bacia Bauru seria constituída por dois grupos parcialmente cronocorrelatos: Grupo Caiuá (formações Rio Paraná, Goio Erê e Santo Anastácio) e Grupo Bauru (formações Uberaba, Vale do Rio do Peixe, Araçatuba, São José do Rio Preto, Presidente Prudente e Marília, além dos analcimitos Taiúva). Como o objetivo deste estudo não é o estudo do Grupo Bauru, utilizou-se de simples comparação deste com os depósitos cenozóicos, sendo utilizada a distribuição litológica de Almeida et al. (1981): formações Marília, Adamantina, Santo Anastácio e Caiuá.

A primeira referência a depósitos cenozóicos na área de estudos é devida a Rego (1946) no "Planalto de Marília", Planalto Ocidental. O autor referiu-se a depósitos areno-argilosos de origem eólica e inferiu uma correlação temporal destes depósitos com as argilas terciárias descritas na Bacia de São Paulo. Almeida (1964) descreveu na região depósitos cenozóicos em áreas restritas, sem estruturas sedimentares e contendo fragmentos de seixos de quartzo, que teriam resultado do retrabalhamento fluvial do Grupo Bauru.

Penteado \& Ranzani (1973) descreveram colúvios, paleossolos e linhas-de-pedra (stone lines) que formam um depósito detrítico de 1,50 a $10 \mathrm{~m}$ de espessura no município de Marília. Queiroz Neto et al. (1977) reconheceram sobre o Planalto de Marília dois níveis geomorfológicos: nível superior (recoberto por depósitos descritos por Rego (1946) e identificados por Penteado \& Ranzani (1973) e nível inferior (com linhas-depedra basais). Penteado \& Ranzani (1973) e Melo \& Ponçano (1983) concluíram que os depósitos do nível superior (Queiroz Neto et al. 1977, Rego 1946) estariam relacionados à época de elaboração de uma superfície de idade mais antiga que os depósitos do nível inferior (Carvalho 1976, Queiroz Neto et al. 1977, Lepsch 1977). Dessa forma os autores consideraram que o nível atualmente inferior teria resultado do retrabalhamento de rochas do Grupo Bauru e do material que hoje se encontra em cotas superiores. Queiroz Neto \& Journaux (1978) consideraram que o nível mais elevado (Queiroz Neto et al. 1977) representaria um remanescente do pediplano de idade terciária média (Superfície Paleogênica ou das Cristas Médias) e os depósitos de nível inferior, entre Marília e Echaporã, corresponderiam a uma fase Neogênica da evolução da drenagem, relacionada à elaboração dos extensos pediplanos. Fúlfaro \& Bjornberg (1994) descrevem no Planalto Ocidental Paulista coberturas aluviais e coluviais associados a dois ciclos geomorfológicos, Sul-Americano (King 1956) e Velhas, formados predominantemente por dois ciclos sedimentares: ciclo inferior de origem aluvial e ciclo superior de origem coluvial. A Superfície Sul-Americana, segundo dados recentes de Ferrari et al. (2001), seria do fim do Cretáceo, pois a datação de derrame de rocha vulcânica alcalina superposto for-

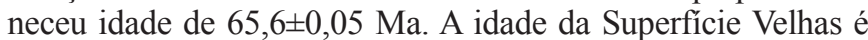
incerta, podendo ser neogênica (Mioceno e/ou Plioceno).

Ponçano et al. (1981) descreveram depósitos coluvionares, na área de estudos, associados a relevos suaves que refletiriam granulometria e composição mineralógica correlacionáveis às rochas basais. Seriam depósitos arenosos de alta permeabilidade e porosidade, que conteriam fragmentos centimétricos dispersos de restos vegetais carbonizados, e apresentariam em média $8 \mathrm{~m}$ de espessura, exibindo na base linha-de-pedra limonitizada e/ou constituída de fragmentos de canga.

No extremo oeste do Estado de São Paulo, Suarez (1976,
1991) descreveu depósitos cenozóicos areno-argilosos e avermelhados, levemente compactados, apresentando "estruturas de dissipação", com freqüentes linhas-de-pedra de provável origem fluvial, e concreções ferruginosas, que o autor denominou de Formação Piquerobi. Suarez (1991) correlacionou esta formação a restos da Superfície Neogênica definida por Ab'Saber (1969), do Terciário Superior, mas nunca foi datada ou proposta formalmente como uma unidade litoestratigráfica.

Segundo Melo \& Ponçano (1983) ocorrem os seguintes depósitos cenozóicos na região de estudo:

a) Coberturas dos platôs de Echaporã e Marília: nesses platôs existiriam depósitos arenosos a areno-argilosos contendo cascalhos avermelhados, que foram provisoriamente correlacionados à Formação Itaqueri (Freitas 1955). Tentativamente, esses depósitos de cobertura foram atribuídos à fase de pediplanação $\mathrm{Pd}_{2}$ de Bigarella \& Andrade (1965). Lepsh (1977) e outros autores admitiram que a cota entre 480-500 m corresponderia ao $\mathrm{Pd}_{1}$ de Bigarella \& Andrade (1965). As informações a respeito dessas coberturas são muito confusas, pois esses autores correlacionam depósitos sedimentares a fases de pediplanação de forma inconsistente, fundamentados em conceitos vagamente estabelecidos.

b) Linhas-de-pedra: associadas aos topos dos platôs residuais (morros-testemunho), sustentados pela Formação Marília, ocorrem vários níveis de linhas-de-pedra de quartzo e quartzito. Os autores atribuem à formação das linhas-de-pedra a fases de pedimentação, baseados na situação estratigráfica atual desses depósitos.

c) Colúvios atuais e subatuais: colúvios arenosos avermelhados e sem coesão, com espessuras de até $30 \mathrm{~m}$, ocupam partes baixas das escarpas de Marília e Echaporã, e conteriam fragmentos vegetais carbonizados. Provavelmente, representariam retrabalhamentos dos depósitos superficiais descritos por Lepsch (1977), mas nenhum dado a respeito da gênese e muito menos sobre a idade desses depósitos estava disponível.

Fúlfaro \& Suguio (1974) descreveram depósitos de areias e colúvios que ocorreriam nos atuais divisores de drenagens do Planalto Ocidental Paulista. Apresentam um nível base de cascalhos com seixos de quartzito e calcedônia ou fragmentos retrabalhados de "limonita", dificilmente individualizados quando não há cascalhos na base. Esses depósitos seriam mal estruturados e confundidos com elúvios, pois pouco se diferenciariam do material de alteração das rochas regionais, denotando sempre pequeno transporte.

Etchebehere et al. (1999) e Etchebehere (2000) mapearam, nos depósitos de terraços no Vale do Rio do Peixe, cinco alomembros que formariam a Aloformação Rio do Peixe, de idade neopleistocênica. Essa aloformação estaria assentada sobre rochas dos Grupos Bauru e Caiuá, apresentaria até $40 \mathrm{~m}$ de espessura em associação a outros depósitos cenozóicos, como leques aluviais tecnogênicos, colúvios holocênicos, alúvios atuais e mantos regolíticos. Os alomembros apresentariam uma associação de fácies similares de corpos arenosos e areno-cascalhosos maciços ou com estratificações acanaladas, bancos de cascalho, siltes e argilas ricos em macrorrestos vegetais (idade radiocarbono entre 27.000 a 34.000 anos A.P.) depositados em um contexto fluvial entrelaçado, com ocorrência de fácies lacustres. Os autores teriam identificado evidências de deformação em depósitos da Aloformação Rio do Peixe, representadas por estruturas de liquefação e falhas de rejeitos diversificados. Dobras e fraturas nos depósitos coluviais que recobririam essa aloformação, também evidenciariam a neotectônica na área. 
Riccomini (1995) teria reconhecido evidências diretas de neotectonismo no Platô de Marília, onde linhas-de-pedra superpostas à Formação Adamantina estariam seccionadas por falhas normais com rejeito decimétrico, que sugeririam extensão na direção WNW.

MATERIAIS E MÉTODOS Foram conduzidos trabalhos de campo, que consistiram em levantamento de perfis geológicos em detalhe distribuídos por toda a área de estudo, considerando-se a geomorfologia e estratigrafia dos afloramentos, acompanhados de coleta de amostras para análises sedimentológicas e datações absolutas por Termoluminescência (TL) e Luminescência Opticamente Estimulada (LOE) (Figura 3). A análise estratigráfica adotada objetivou o reconhecimento de unidades morfoestratigráficas (Frye \& Willman 1962) em superfícies deposicionais.

As análises sedimentológicas, de sedimentos inconsolidados e de rochas sedimentares coletados na área de estudo, consistiram na caracterização textural, por análise granulométrica convencional e caracterização mineralógica da fração areia. Inicialmente foi adotado o peneiramento para partículas maiores que 0,062 $\mathrm{mm}$ e a pipetagem para frações menores, utilizando-se a escala granulométrica de Wentworth (1922). Posteriormente a separação dos minerais leves e pesados foi efetuada por diferenças de densidades dos minerais das amostras (Parfenoff et al. 1970, Carver 1971) em um líquido denso (bromofórmio - $\mathrm{CHBr}_{3}$ ). Para melhor interpretar os significados das assembléias de minerais pesados transparentes e não-micáceos encontrados, foram determinados os valores de índice ZTR, que reflete a maturidade mineralógica correspondendo à soma das porcentagens relativas de ocorrências de zircão, turmalina e rutilo entre esses minerais.

Foram empregadas técnicas de geoprocessamento e observações de campo para a caracterização morfoestrutral da área de estudo e identificação dos depósitos quaternários, correlacionando-os a níveis geomorfológicos. Foram utilizados produtos de sensoriamento remoto, a partir de recortes georreferenciados de quatro imagens multiespectrais do sensor ETM+ do satélite LANDSAT-7 (obtidas em 05 e 12/08/2001) e geradas cartas te- máticas com a geração de Modelo Digital de Terreno (MDT), mapas hipsométrico, declividade e orientação de encostas, rugosidade e densidade de drenagem. A caracterização morfoestrutural foi fundamentalmente baseada nos comportamentos da rede de drenagem e nos aspectos texturais, tendo como base o mapeamento geomorfológico realizado por Ponçano et al. (1981).

Datação por Termoluminescência (TL) e Luminescência Opticamente Estimulada (LOE) Com o objetivo de tentar identificar gerações de depósitos coluviais e aluviais foram datados sedimentos arenosos por TL e LOE. Estes métodos mostram grande potencialidade para depósitos siliciclásticos quaternários, quando o quartzo é o constituinte mineral predominante e, além disso, permite alcançar idades muito mais antigas do que pelo método de radiocarbono. A luminescência refere-se à propriedade física de materiais cristalinos ou vítreos, previamente irradiados com uma radiação ionizante, de emitir luz quando são aquecidos até determinadas temperaturas. O método de datação por luminescência é fundamentado na teoria da interação da radiação com a matéria, pois se baseia no fato de que a idade do material a ser datado pode ser calculada pela medida das concentrações de defeitos induzidos no material por radiações ionizantes.

Materiais geológicos e arqueológicos, tais como alguns minerais e fragmentos de cerâmica, recebem radiações ionizantes provenientes dos raios cósmicos e de radioisótopos naturais, que se encontram no seu interior ou na vizinhança. Parte desta radiação provoca ionização por efeito fotoelétrico, efeito de Compton e produção de pares, podendo os elétrons liberados produzir defeitos pontuais ou vários tipos de centros. Estes centros resultam da captura de elétrons ou buracos (carga positiva) por estados metaestáveis criados por defeitos e impurezas. Quando a amostra é aquecida, os elétrons aprisionados são liberados e podem se recombinar com um buraco, emitindo luz luminescente. O número desses centros, dentro de certos limites, cresce proporcionalmente à dose de radiação incidente e ao tempo de irradiação. Assim, medindo-se a luz emitida por esses centros por estimulação térmica é possível, por exemplo, determinar quando um

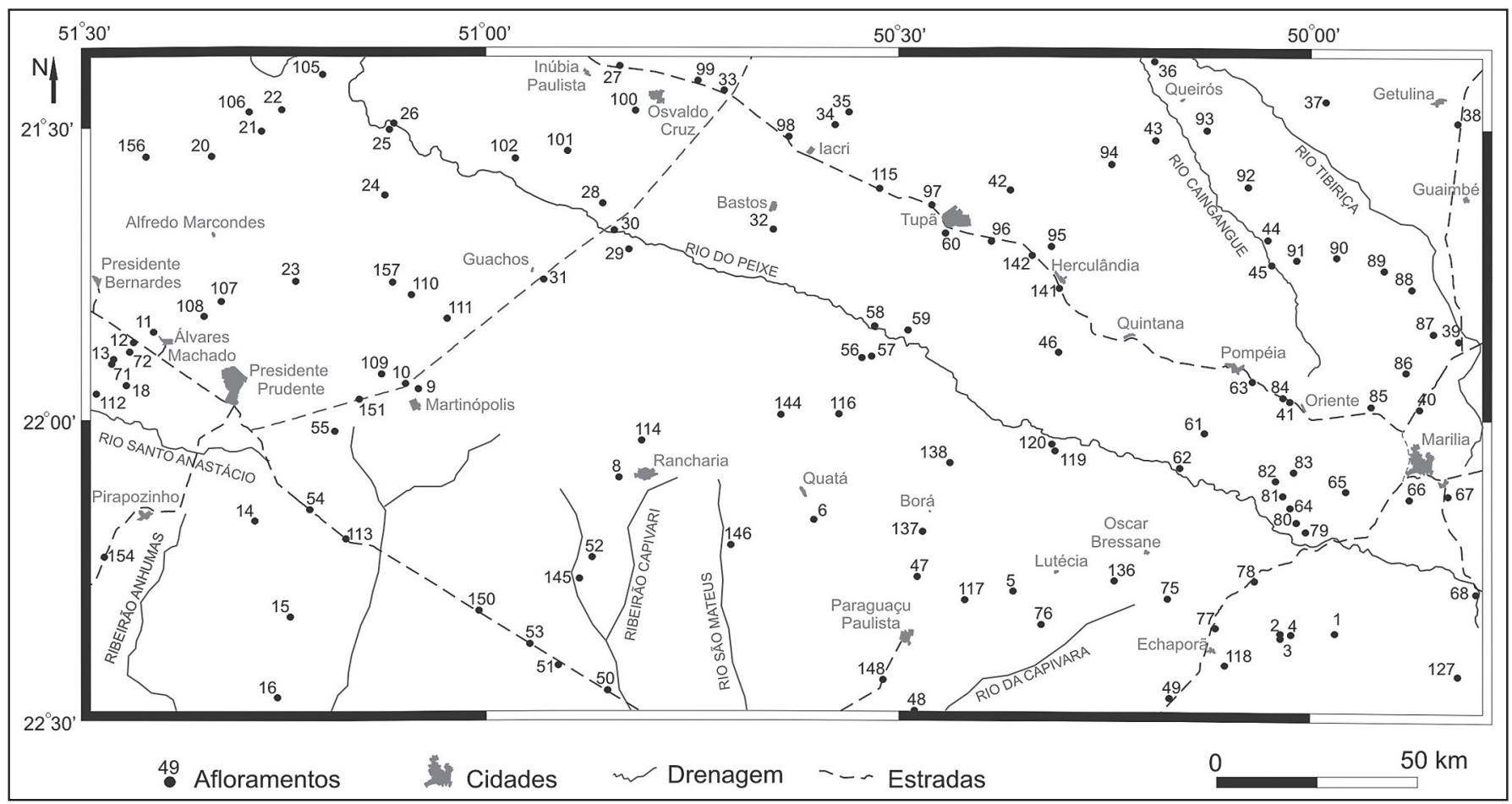

Figura 3 - Localização dos pontos de descrição geológica na área de estudos. 
mineral se cristalizou ou quando um sedimento foi exposto à luz solar pela última vez por um período mínimo de 6-8 horas (TL) e 2 horas (LOE) (Aitken 1985).

O método de datação por luminescência permite obter idades desde poucas dezenas de anos até cerca de 1,5 Ma anos, dependendo das características da amostra e da sensibilidade do equipamento utilizado na medida. A aplicação na determinação de idade de depósitos sedimentares por este método se iniciou na década de 80 (Wintle \& Huntley 1980).

As amostras coletadas foram peneiradas para separar grãos de 88-180 $\mu \mathrm{m}$ (areia muito fina a fina) e submetidos a um tratamento químico com $\mathrm{HF} 20 \%$ por 45 minutos, $\mathrm{HCl} 20 \%$ durante 2 horas, para então serem selecionados apenas grãos de quartzo. As medidas de TL e LOE foram realizadas com $40 \mathrm{mg}$ de grãos selecionados.

As curvas de luminescência foram obtidas no Laboratório de Vidro da Faculdade de Tecnologia de São Paulo (FATEC-SP), com o aparelho TL/OSL Automated Systems, Model 1100-series Daybreak Nuclear Instruments Inc., com aquecimento de $10^{\circ} \mathrm{C} / \mathrm{s}$., e os grãos de quartzo sofreram uma irradiação com ${ }^{60} \mathrm{Co}$ realizada no IPEN-CNEN/SP. A Dose Acumulada (P) foi obtida através do Método de Regeneração Total. Os valores das doses anuais foram calculados usando as concentrações de ${ }^{40} \mathrm{~K},{ }^{232} \mathrm{Th}$, ${ }^{238} \mathrm{U},{ }^{235} \mathrm{U}$ medidas no Instituto de Pesquisa em Energia Nuclear (IPEN-CNEN/SP) e a contribuição da radiação cósmica utilizada foi de 174,22 $\mu \mathrm{Gy} /$ ano (Sallun et al. 2006).

DEPÓSITOS QUATERNÁRIOS Na área de estudo são encontradas rochas mesozóicas da Bacia do Paraná, representadas pelas formações Serra Geral (Grupo São Bento), Marília e Adamantina (Grupo Bauru) e depósitos quaternários. Foram identificados depósitos arenáceos e rudáceos superpostos a rochas mesozóicas do Grupo Bauru e da formação Serra Geral. Os depósitos quaternários estão distribuídos irregularmente na área de estudo e podem ser agrupados como depósitos colúvioeluviais e aluviais, segundo as semelhanças composicional e relação genética confrontadas com as feições morfológicas da paisagem atual.

Depósitos Colúvio-eluviais Os depósitos colúvio-eluviais ocorrem em toda a área de estudo e são homogêneos, arenáceos a rudáceos e exibem estrutura maciça e espessura de 1 a $9 \mathrm{~m}$. Nos locais de maior espessura ( 5 a 9 m), a cifra medida corresponde ao valor mínimo, pois o contato inferior com as rochas cretáceas e jurássicas não está aflorante. Os depósitos são constituídos de areias muito finas a grossas e inconsolidadas, em sua maioria formada por grãos individuais de quartzo e coloração avermelhada em função de óxidos e hidróxidos de ferro presentes. Em muitas localidades exibem "bandas onduladas", que foram caracterizadas como estruturas de origem pedogenética por Suguio \& Coimbra (1976).

Os contatos entre os depósitos arenosos e as rochas do Grupo Bauru e da Formação Serra Geral são discordantes, porém pela falta de estruturas são confundidos com elúvios, pois pouco se diferenciariam do material de alteração das rochas regionais, denotando sempre pequeno transporte. A grande semelhança em composição (granulometria e mineralogia) entre os depósitos quaternários e os substratos rochosos, em diversas localidades, caracteriza contatos essencialmente "transicionais" sob o ponto de vista pedológico (Figura 4). Dessa forma, esses depósitos são referidos aqui como colúvio-eluviais apesar dos grãos de quartzo oriundos de perfis de sedimentos maciços, sem nenhum hiato deposicional aparente, quando estudados por luminescência demonstram que ocorreu transporte e exposição à luz solar.

Somente a presença de ferricretes e/ou linhas-de-pedra na base dos depósitos quaternários permite reconhecer a existência de um hiato deposicional. Os ferricretes basais formam camadas onduladas, localmente interrompidas, de 2 a $40 \mathrm{~cm}$ de espessura (Figura 5) que contém, além de ferricretes fragmentados, raros seixos arredondados e centimétricos de quartzo e/ou quartzito. Esses níveis sempre ocorrem nos contatos da Formação Adamantina com os depósitos coluviais, ou como fragmentos retrabalhados no meio de depósitos coluviais, que ocorrem sobre as formações Serra Geral, Adamantina ou Marília. As pseudo-dobras podem representar simples acomodação à paleotopografia da antiga superfície, mas as falhas que afetam as camadas de ferricretes seriam atectônicas ou até relacionadas a eventuais atividades neotectônicas. Provavelmente, a origem dos ferricretes está relacionada à dissolução seguida de reprecipitação de hidróxidos de ferro, por oscilações dos níveis de lençol freático, relacionadas a flutuações paleoclimáticas.

Os ferricretes constituem agregados de nódulos irregulares, com dimensões milimétricas a centimétricas, e raras estruturas

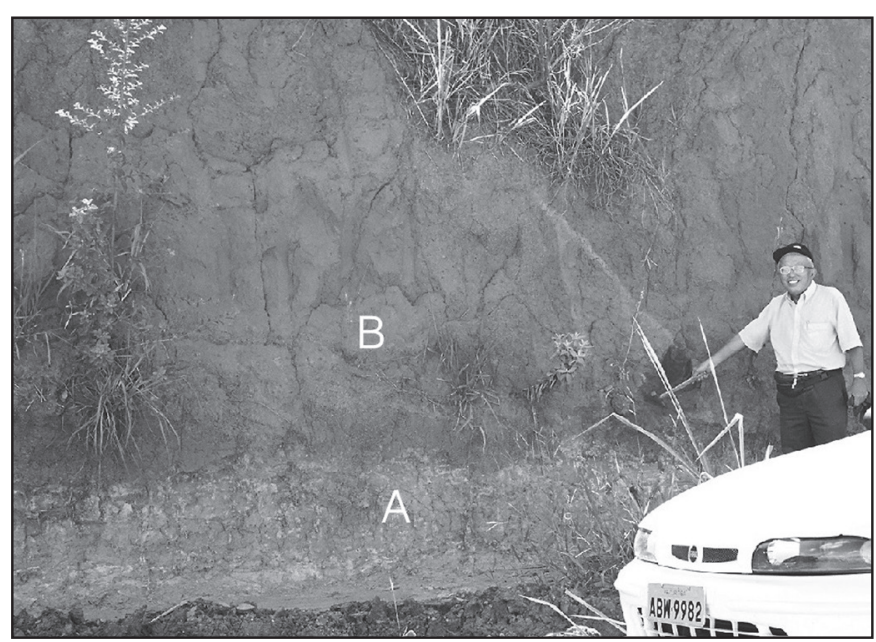

Figura 4 - Depósito colúvio-eluvial (B) e rochas do Grupo Bauru (A), nas proximidades da cidade de Álvares Machado (Ponto 12 - UTM 447554E/7558168N).

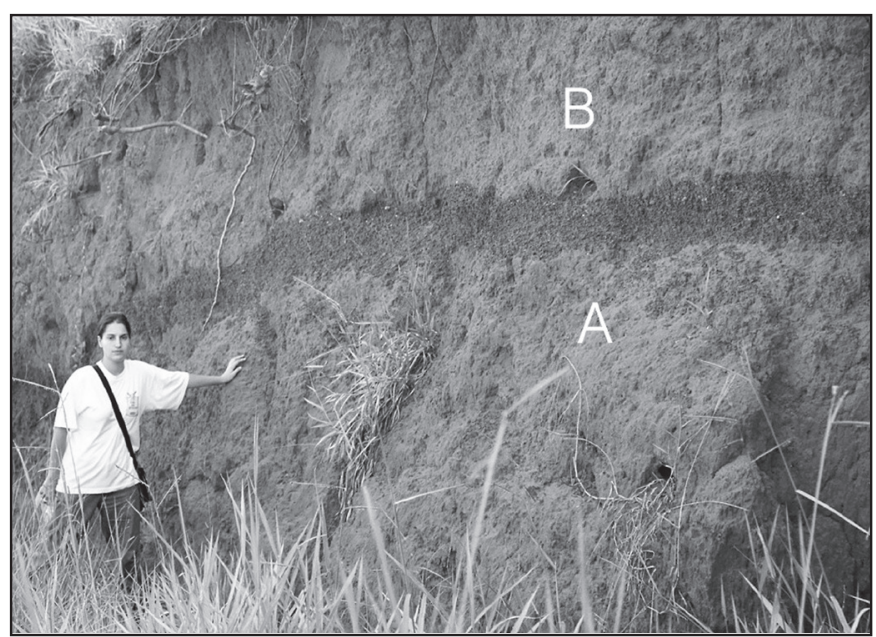

Figura 5 - Camada de fragmentos de ferricretes com espessura irregular, que ocorre entre rochas do Grupo Bauru (A) e depósito colúvio-eluvial (B), que por datação através de $L O E$ (Luminescência Opticamente Estimulada) forneceu idade de $54.000 \pm 6.500$ anos A.P. Este afloramento ocorre nas proximidades da cidade de Sagres (UTM 505599E/7575955N). 
grosseiramente concêntricas de cores marrom-avermelhadas. Na sua composição sobressaem areias finas a grossas e quartzosas, que são cimentadas por goethita (hidróxido férrico). Segundo Bourman (1993), seriam sedimentos clásticos ferricretizados, que estão presentes em 14 localidades da área de estudo nos contatos entre os depósitos colúvio-eluviais e as rochas cretácicas da Formação Adamantina. Ocorrem também como fragmentos incorporados às linhas-de-pedra.

Por estudo petrográfico sob MEV (microscópio eletrônico de varredura) verificou-se que os ferricretes representam areias essencialmente quartzosas cimentadas com baixo conteúdo de goethita. Os grãos de quartzo exibem feições de corrosão (microfissuras), provavelmente ligadas à dissolução por severo intemperismo. As camadas externas de cores amarelas a acastanhadas dos ferricretes são de hematita. Verificam-se também estruturas de preenchimento concêntrico, por óxidos de ferro, da porosidade intersticial dos grãos de areia. Sendo o quartzo o principal mineral constituinte dos ferricretes, análises químicas acusaram altos teores de $\mathrm{SiO}_{2}$ (Figura 6).

Sobre a Formação Marília ocorrem depósitos colúvio-eluviais rudáceos, que são representativos de intenso intemperismo provavelmente formados in situ através de curto transporte por rastejo. Esses depósitos são maciços e possuem até $7 \mathrm{~m}$ de espessura no platô de Marília. São ortoconglomerados em geral oligomíticos e, sem arranjo interno, que contêm desde grânulos a matacões subarredondados a arredondados, características provavelmente herdadas da rocha matriz. Os fragmentos exibem contatos pontuais e localmente côncavo-convexos, cujos diâmetros maiores podem chegar a $15 \mathrm{~cm}$. Os seixos predominantes são de quartzo e quartzito, além de raros seixos de sílex e basalto. A matriz argilosa não ultrapassa $15 \%$ e, além disso, surgem intercalações de camadas arenosas com até $15 \mathrm{~cm}$ de espessura.

As análises granulométricas mostraram que os depósitos colúvio-eluviais apresentam 13 classes texturais e as curvas acumulativas de distribuição granulométrica total demonstram o caráter homogêneo desses depósitos. Eles apresentam distribuição total com contribuição maior de areia argilosa que as rochas do Grupo Bauru.

O estudo microscópico de minerais pesados transparentes não-micáceos mostrou que, tanto nas areias finas como muito finas, quatro minerais (zircão, turmalina, estaurolita, rutilo) es- tão presentes em todas as amostras analisadas e, conjuntamente com a cianita foram então classificados como superabundantes. Os minerais considerados abundantes são representados pela sillimanita, granada e augita, e os minerais comuns por epídoto e egirina. Em mais de $25 \%$ das amostras analisadas, apenas seis minerais (zircão, turmalina, estaurolita, rutilo, cianita e sillimanita) estavam presentes nas areias fina $(0,250-0,125 \mathrm{~mm}) \mathrm{e}$ muito fina $(0,125-0,062 \mathrm{~mm})$. Entretanto, na areia muito fina zircão, rutilo e estaurolita apresentam maior freqüência.

Todas as amostras de depósitos colúvio-eluviais datadas pelos métodos de TL e de LOE exibem idade pleistocênica, $9.000 \pm 1.000$ a $980.000 \pm 100.000$ anos A.P. (Tabela 1), sendo que as mesmas amostras datadas por TL e LOE não mostraram diferença significativa no resultado. As idades obtidas e a distribuição espacial dos depósitos sugere que as idades desses depósitos estejam intimamente ligadas a níveis topográficos diferentes. As idades obtidas dos depósitos coluviais superpostos às camadas de ferricretes sugerem que não representam uma única geração (Tabela 1), mas vários ciclos de formação de crostas ferríferas. Entretanto, as semelhanças texturais (granulometria) e composicionais (química e mineralógica) poderiam ser sugestivas de uma única fase de formação, com idade mínima de $402.000 \pm 40.000$ anos A.P.

Depósitos Aluviais Foram identificados terraços fluviais associados a diferentes níveis topográficos nas bacias dos rios do Peixe, Paranapanema, Santo Anastácio e Aguapeí (Figura 7), constituídos de depósitos arenáceos e rudáceos. Os arenáceos são compostos por areia inconsolidada esbranquiçada e com estrutura maciça. Os rudáceos se situam entre 365 a 420 $\mathrm{m}$ de altitude, 45 a $60 \mathrm{~m}$ acima da drenagem atual. Depósitos rudáceos com até $6 \mathrm{~m}$ de espessura são representados por ortoconglomerados oligomíticos, sem arranjo interno, compostos de grânulos a seixos subarredondados a arredondados de até 6 $\mathrm{cm}$ de diâmetro maior, essencialmente formados por quartzo e quartzito, com proporções bem menores de basalto e granito. A coloração avermelhada, devida a óxidos e hidróxidos de ferro, é encontrada em matriz arenosa, que perfaz cerca de $15 \%$ do volume total.

As análises granulométricas mostraram que os depósitos aluviais são compostos de 12 classes texturais e as curvas acumulativas da distribuição total demonstram o caráter em geral
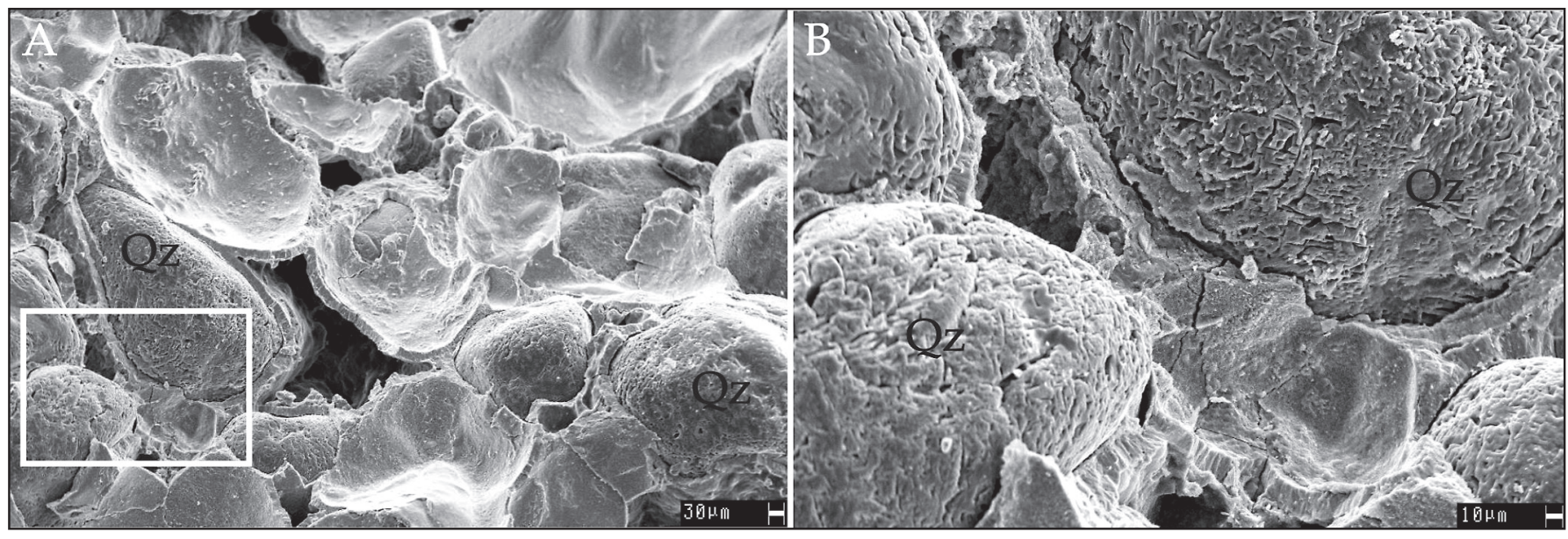

Figura 6 - Fotomicrografias obtidas por MEV de fragmento de ferricrete. Este ferricrete ocorre nas proximidades da cidade de Paraguaçu Paulista (Ponto 48 - UTM 544482E/7511382N), entre rochas da Formação Serra Geral e depósito coluvial, que por datação através de TL forneceu idade de 41.000 4.000 anos A.P. A) Observam-se grãos de quartzo "encapados" por cimento ferruginoso e a porosidade entre os grãos; B) Detalhe de (A) onde se observa a corrosão que ocorre na superficie dos grãos de quartzo $(Q z=$ quartzo $)$. 
Tabela 1 - Dados obtidos das datações por TL e LOE de depósitos colúvio-eluviais (* = amostra proveniente de depósito coluvial superposto a camada de ferricrete)

\begin{tabular}{|c|c|c|c|c|c|}
\hline amostra & $\begin{array}{c}{ }^{235} \mathbf{U}+{ }^{238} \mathbf{U} \\
(\text { ppm) }\end{array}$ & $\begin{array}{l}{ }^{232} \mathbf{T h} \\
(\mathrm{ppm})\end{array}$ & $\begin{array}{l}{ }^{40} \mathbf{K} \\
(\%)\end{array}$ & $\begin{array}{c}\text { Idade TL } \\
\text { (x10 } \text { anos A.P.) }\end{array}$ & $\begin{array}{c}\text { Idade LOE } \\
\left(\times 10^{3} \text { anos A.P.) }\right.\end{array}$ \\
\hline 04 & $1.70 \pm 0.01$ & $4.97 \pm 0.14$ & $0.002 \pm 0.01$ & $125 \pm 12$ & $127 \pm 12$ \\
\hline 06 & $1.07 \pm 0.02$ & $3.20 \pm 0.09$ & $0 \pm 0.01$ & - & $128 \pm 14$ \\
\hline 08 & $1.15 \pm 0.03$ & $3.53 \pm 0.11$ & $0 \pm 0.01$ & - & $487 \pm 51$ \\
\hline 09 & $1.85 \pm 0.05$ & $5.07 \pm 0.15$ & $0.052 \pm 0.01$ & - & $307 \pm 36$ \\
\hline 11 & $1.68 \pm 0.04$ & $6.68 \pm 0.20$ & $0.07 \pm 0.01$ & $19 \pm 2$ & $22 \pm 2$ \\
\hline 14 & $1.06 \pm 0.03$ & $4.37 \pm 0.13$ & $0.002 \pm 0.01$ & $206 \pm 20$ & - \\
\hline 16 & $1.47 \pm 0.03$ & $2.17 \pm 0.06$ & $0 \pm 0.01$ & $42 \pm 5$ & - \\
\hline $19 *$ & $1.74 \pm 0.04$ & $5.41 \pm 0.16$ & $0.04 \pm 0.01$ & $34 \pm 3$ & - \\
\hline 25 & $1.87 \pm 0.04$ & $6.22 \pm 0.18$ & $0 \pm 0.01$ & $13 \pm 1$ & $37 \pm 2$ \\
\hline 27 & $1.04 \pm 0.02$ & $2.62 \pm 0.07$ & $0 \pm 0.01$ & $10 \pm 1$ & - \\
\hline $28 *$ & $1.10 \pm 0.02$ & $3.23 \pm 0.09$ & $0.002 \pm 0.01$ & - & $54 \pm 5$ \\
\hline 31 & $1.07 \pm 0.02$ & $1.39 \pm 0.04$ & $0 \pm 0.01$ & $159 \pm 17$ & - \\
\hline 35 & $1.41 \pm 0.03$ & $1.69 \pm 0.05$ & $0.02 \pm 0.01$ & $21 \pm 2$ & $22 \pm 1$ \\
\hline $43 *$ & $1.18 \pm 0.03$ & $2.26 \pm 0.02$ & $0 \pm 0.01$ & $51 \pm 5$ & - \\
\hline $45 *$ & $1.57 \pm 0.04$ & $2.32 \pm 0.06$ & $0 \pm 0.01$ & $74 \pm 8$ & - \\
\hline $48 *$ & $1.86 \pm 0.04$ & $4.09 \pm 0.12$ & $0.004 \pm 0.01$ & $41 \pm 4$ & - \\
\hline 50 & $0.86 \pm 0.02$ & $1.71 \pm 0.01$ & $0 \pm 0.01$ & $980 \pm 100$ & - \\
\hline 59 & $1.24 \pm 0.03$ & $3.05 \pm 0.09$ & $0 \pm 0.01$ & $28 \pm 3$ & - \\
\hline $67 *$ & $1.09 \pm 0.02$ & $1.49 \pm 0.04$ & $0 \pm 0.01$ & $92 \pm 10$ & - \\
\hline 75 & $1.23 \pm 0.03$ & $4.72 \pm 0.14$ & $0.09 \pm 0.01$ & $57 \pm 4$ & - \\
\hline 77 & $1.25 \pm 0.03$ & $4.91 \pm 0.15$ & $0 \pm 0.01$ & $34 \pm 3$ & - \\
\hline 84 & $0.91 \pm 0.02$ & $1.89 \pm 0.06$ & $0 \pm 0.01$ & $920 \pm 74$ & - \\
\hline 87 & $1.11 \pm 0.02$ & $1.009 \pm 0.03$ & $0.022 \pm 0.01$ & $138 \pm 15$ & - \\
\hline 94 & $1.12 \pm 0.03$ & $2.16 \pm 0.07$ & $0 \pm 0.01$ & $32 \pm 4$ & - \\
\hline $102 *$ & $1.26 \pm 0.03$ & $2.15 \pm 0.06$ & $0.04 \pm 0.01$ & $62 \pm 6$ & - \\
\hline 105 & $1.33 \pm 0.04$ & $2.34 \pm 0.07$ & $0 \pm 0.01$ & $30 \pm 2$ & $36 \pm 8$ \\
\hline $108 *$ & $2.65 \pm 0.06$ & $5.38 \pm 0.16$ & $0.11 \pm 0.01$ & $402 \pm 40$ & - \\
\hline 113 & $1.11 \pm 0.03$ & $1.08 \pm 0.03$ & $0.04 \pm 0.01$ & $35 \pm 4$ & - \\
\hline 114 & $0.98 \pm 0.02$ & $1.29 \pm 0.04$ & $0 \pm 0.01$ & $63 \pm 7$ & - \\
\hline 115 & $1.15 \pm 0.03$ & $1.78 \pm 0.05$ & $0 \pm 0.01$ & $232 \pm 19$ & - \\
\hline 116 & $1.12 \pm 0.03$ & $1.92 \pm 0.03$ & $0 \pm 0.01$ & $30 \pm 2$ & $40 \pm 3$ \\
\hline 117 & $0.81 \pm 0.02$ & $1.08 \pm 0.03$ & $0 \pm 0.01$ & $41 \pm 5$ & - \\
\hline 127 & $0.84 \pm 0.02$ & $1.47 \pm 0.04$ & $0 \pm 0.01$ & $130 \pm 10$ & - \\
\hline 136 & $0.97 \pm 0.02$ & $1.45 \pm 0.04$ & $0 \pm 0.01$ & $25 \pm 2$ & $38 \pm 3$ \\
\hline 137 & $0.81 \pm 0.02$ & $1.29 \pm 0.04$ & $0 \pm 0.01$ & $60 \pm 5$ & - \\
\hline 142 & $1.08 \pm 0.03$ & $0.92 \pm 0.03$ & $0 \pm 0.01$ & $18 \pm 2$ & $31 \pm 4$ \\
\hline 138 & $0.98 \pm 0.03$ & $1.24 \pm 0.04$ & $0 \pm 0.01$ & $9,2 \pm 0,8$ & $13 \pm 1$ \\
\hline 144 & $1.03 \pm 0.03$ & $1.85 \pm 0.06$ & $0 \pm 0.01$ & $36 \pm 3$ & $35 \pm 4$ \\
\hline 145 & $0.56 \pm 0.02$ & $1.44 \pm 0.01$ & $0 \pm 0.01$ & $10,1 \pm 0,8$ & $9 \pm 1$ \\
\hline 146 & $0.62 \pm 0.02$ & $0.52 \pm 0.02$ & $0.02 \pm 0.01$ & $402 \pm 31$ & - \\
\hline 148 & $0.35 \pm 0.01$ & $0.27 \pm 0.01$ & $0 \pm 0.01$ & $30 \pm 2$ & $23 \pm 1$ \\
\hline 150 & $1.12 \pm 0.03$ & $2.25 \pm 0.02$ & $0 \pm 0.01$ & $249 \pm 19$ & - \\
\hline 151 & $0.95 \pm 0.02$ & $0.92 \pm 0.03$ & $0 \pm 0.01$ & $188 \pm 15$ & - \\
\hline 154 & $1.04 \pm 0.03$ & $1.21 \pm 0.04$ & $0.04 \pm 0.01$ & $144 \pm 10$ & - \\
\hline $156^{*}$ & $1.06 \pm 0.03$ & $1.31 \pm 0.04$ & $0 \pm 0.01$ & $23 \pm 2$ & $42 \pm 3$ \\
\hline $157 *$ & $0.91 \pm 0.02$ & $1.23 \pm 0.04$ & $0 \pm 0.01$ & $32 \pm 3$ & $34 \pm 7$ \\
\hline
\end{tabular}


homogêneo desses depósitos. As distribuições totais desses depósitos são compostas, predominantemente por areias e areias argilosas.

Todas as amostras de depósitos aluviais datadas pelos métodos de TL e LOE exibem idade pleistocênica, $14.000 \pm 2.000$ a $240.000 \pm 30.000$ anos A.P. (Tabela 2), sendo que as mesmas amostras datadas por TL e LOE não mostraram diferença significativa no resultado. Para amostras coletadas em terraços altos (bacias do Rio do Peixe e do Paranapanema) foram obtidas idades mais antigas $(240.000 \pm 30.000$ e $70.000 \pm 5.000$ anos A.P.) do que as amostras coletadas em terraços baixos (bacias do

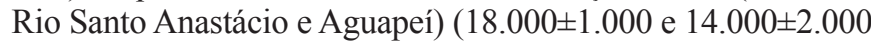
anos A.P.). Provavelmente os terraços altos são mais antigos que os terraços baixos, e pode-se concluir que as bacias de drenagem que ocorrem na área de estudos estão atuando desde 240.000 anos A.P. até os dias atuais no afeiçoamento do relevo, de forma construtiva (terraços) e destrutiva (dissecação). A posição topográfica desses terraços nos indica que o nível de base da região, desde esta época, vem sendo rebaixado ao longo do tempo.

PROVENIÊNCIA DOS DEPÓSITOS COLÚVIO-ELUVIAIS Para efeito de comparação com os depósitos quaternários foram também analisadas amostras de arenitos que ocorrem sotopostos, das formações Adamantina e Marília do Grupo Bauru. Os resultados das distribuições granulométricas totais das amostras indicam que os teores de argila são mais altos em depósitos colúvio-eluviais do que no Grupo Bauru. Em relação às distribuições granulométricas das areias, quando localizados em mesmos afloramentos, as amostras exibiram boas correlações.

As diferenças constatadas entre os depósitos colúvio-elu-

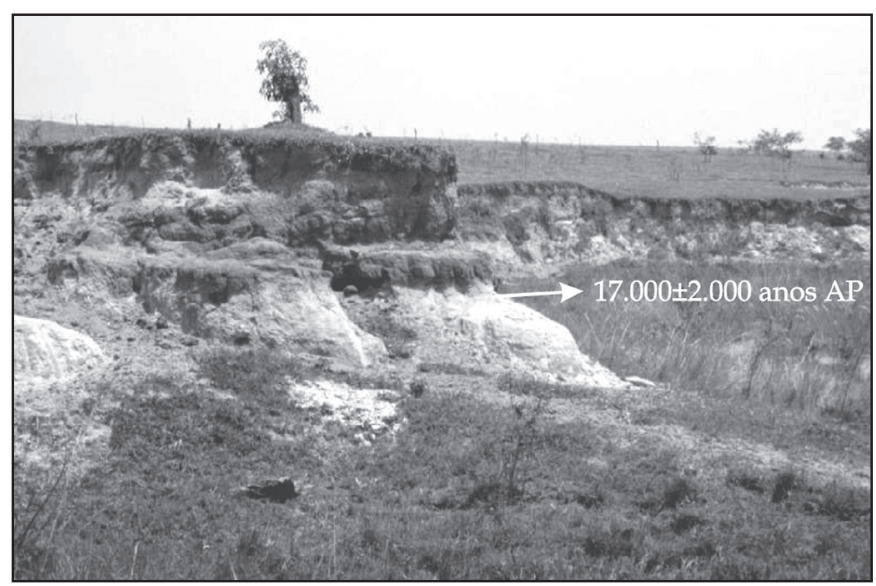

Figura 7 - Extenso terraço fluvial baixo no Rio Caingangue, afluente do Rio Aguapeí, cuja datação indicou idade de $17.000 \pm 2.000$ anos A.P. por TL e 18.000 1.000 anos A.P. por LOE. Este afloramento ocorre nas proximidades da cidade de Novo Cravinhos (Ponto 91 - UTM 592480E/7568463N). viais e as rochas sotopostas do Grupo Bauru são perfeitamente explicáveis pelo enriquecimento dos depósitos quaternários em argila por processos pedogenéticos. Em termos de distribuições granulométricas das frações arenosas a variabilidade é menor nos depósitos quaternários, talvez em função da atenuação pelos mesmos processos pedogenéticos.

Em geral, os depósitos colúvio-eluviais caracterizam-se por exibirem altas maturidades mineralógicas, que são expressas por valores mais altos de índice ZTR, que foram 76 a $97 \%$ e 79 a $96 \%$ nas frações de areias fina e muito fina, respectivamente. Enquanto isso, os valores deste índice variam de 53 a 100\% e 67 a $98 \%$, nas mesmas frações nas rochas sedimentares do Grupo Bauru (Figura 8).

Embora os conteúdos de minerais pesados mostrem boa correlação entre amostras de depósitos quaternários e de rochas, cretácicas dos mesmos afloramentos, parece ocorrer enriquecimento em minerais ultraestáveis em depósitos colúvio-eluviais. Este fato poderia ser explicado também pela pedogênenese. Além disso, confrontando-se as assembléias de minerais pesados de depósitos quaternários e de rochas cretácicas, dos mesmos afloramentos, nota-se a presença de alguns minerais de origem metamórfica, que aparecem somente nos depósitos colúvio-eluviais. Este fato poderia sugerir eventual contribuição por processos de transporte eólico ou por rastejo de afloramentos a rochas do Grupo Bauru, que continham esses minerais pesados e se situavam nas vizinhanças.

\section{GEOMORFOLOGIA E DEPÓSITOS COLÚVIO-ELU-}

VIAIS A partir de estudos geomorfológicos foram identificadas regiões com predomínio de processos morfogenéticos e pedogenéticos, caracterizadas por depósitos colúvio-eluviais bem desenvolvidos. As características das feições geomorfológicas são controladas, entre outros fatores, por diferenças litológicas e direções preferenciais de lineamentos, que condicionam os escoamentos das águas superficiais. As distribuições das diferentes formações do Grupo Bauru, da Formação Serra Geral do Grupo São Bento, de espessas coberturas colúvio-eluviais e de algumas estruturas tectônicas poderiam ser responsáveis pela compartimentação do relevo regional. As rochas sedimentares da Formação Marília originaram relevos cuestiformes, com morros-testemunho e espigões alongados na direção E-W, em função da maior resistência à erosão devida à intensa cimentação carbonática (Figura 9).

A área é coberta por rede de drenagem em geral dendrítica, subordinada a juntas tectônicas e a litologias mais resistentes ao intemperismo e à erosão e, desta maneira, alguns dos canais principais seguem lineamentos estruturais, definindo padrões retilíneos. Os canais dos rios do Peixe e Aguapeí são encaixados e exibem padrão meandrante e os seus afluentes assumem padrão subdendrítico. Quando a cobertura quaternária porosa e permeável é mais espessa, a densidade de drenagem torna-se mais baixa, pelo predomínio de infiltração de águas pluviais.

Alguns dos fatos mais importantes relacionados aos depó-

Tabela 2 - Dados obtidos das datações por TL e LOE de depósitos aluviais.

\begin{tabular}{|c|c|c|c|c|c|}
\hline amostra & $\begin{array}{c}{ }^{235} \mathbf{U}+{ }^{238} \mathbf{U} \\
(\mathbf{p p m})\end{array}$ & $\begin{array}{c}{ }^{232} \mathbf{T h} \\
\mathbf{( p p m )}\end{array}$ & $\begin{array}{c}{ }^{40} \mathbf{K} \\
\mathbf{( \% )}\end{array}$ & $\begin{array}{c}\text { Idade TL } \\
\left(\mathbf{1 0}^{3} \text { anos A.P.) }\right.\end{array}$ & $\begin{array}{c}\text { Idade LOE } \\
\left(\mathbf{1 0} \mathbf{1}^{\mathbf{3}} \text { anos A.P. }\right)\end{array}$ \\
\hline 05 & $1.06 \pm 0.03$ & $0.80 \pm 0.02$ & $0 \pm 0.01$ & $64 \pm 7$ & $70 \pm 5$ \\
\hline 81 & $0.33 \pm 0.01$ & $0.60 \pm 0.01$ & $0 \pm 0.01$ & $215 \pm 30$ & $240 \pm 30$ \\
\hline 91 & $0.55 \pm 0.01$ & $1.00 \pm 0.01$ & $0 \pm 0.01$ & $17 \pm 2$ & $18 \pm 1$ \\
\hline 112 & $1.01 \pm 0.02$ & $1.01 \pm 0.02$ & $0 \pm 0.01$ & $28 \pm 3$ & $14 \pm 2$ \\
\hline
\end{tabular}



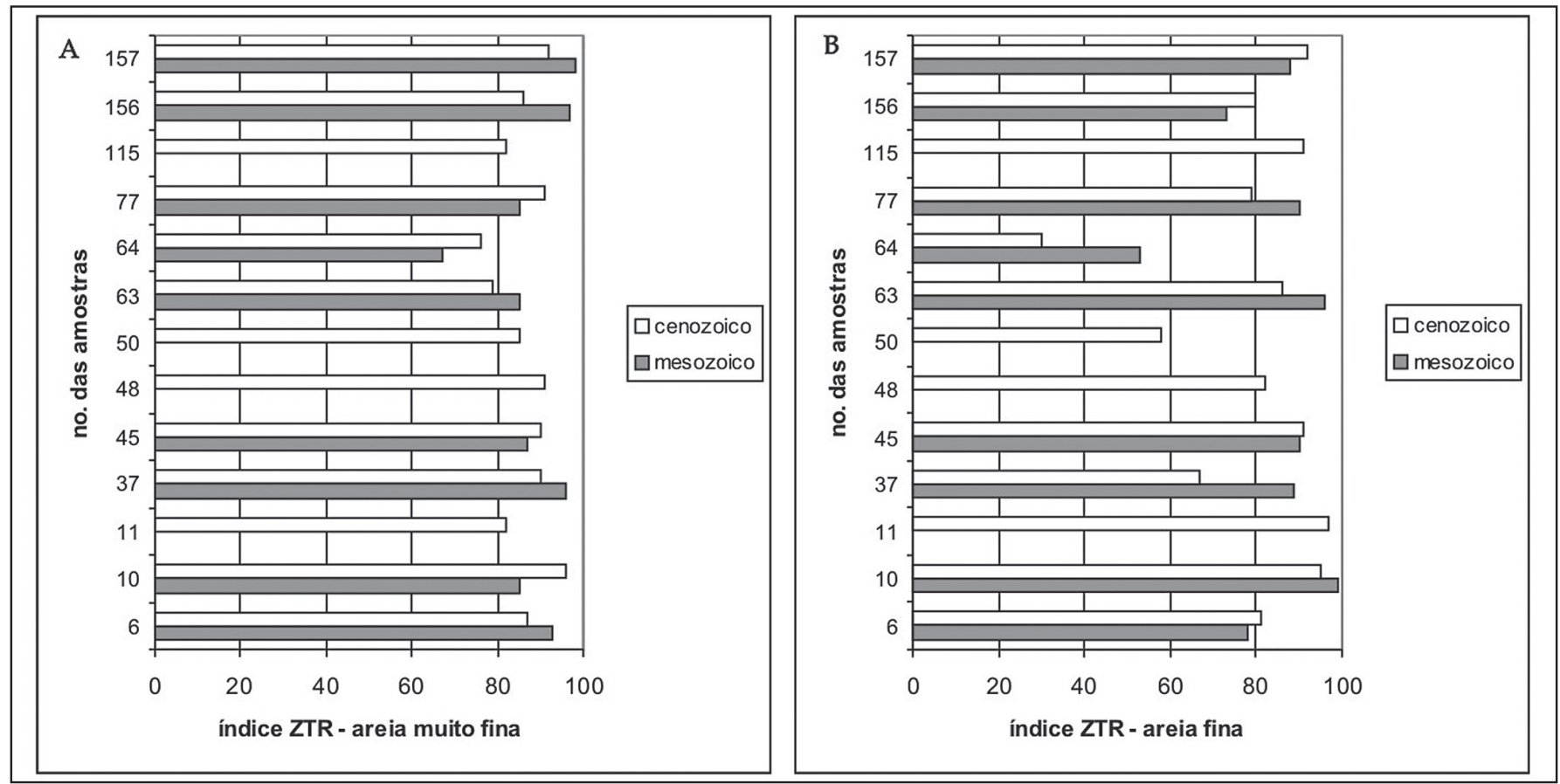

Figura 8 - Distribuição do índice ZTR nos depósitos colúvio-eluviais (cenozóico) e no Grupo Bauru (mesozóico) para as distribuições areia muito fina (A) e areia fina (B).

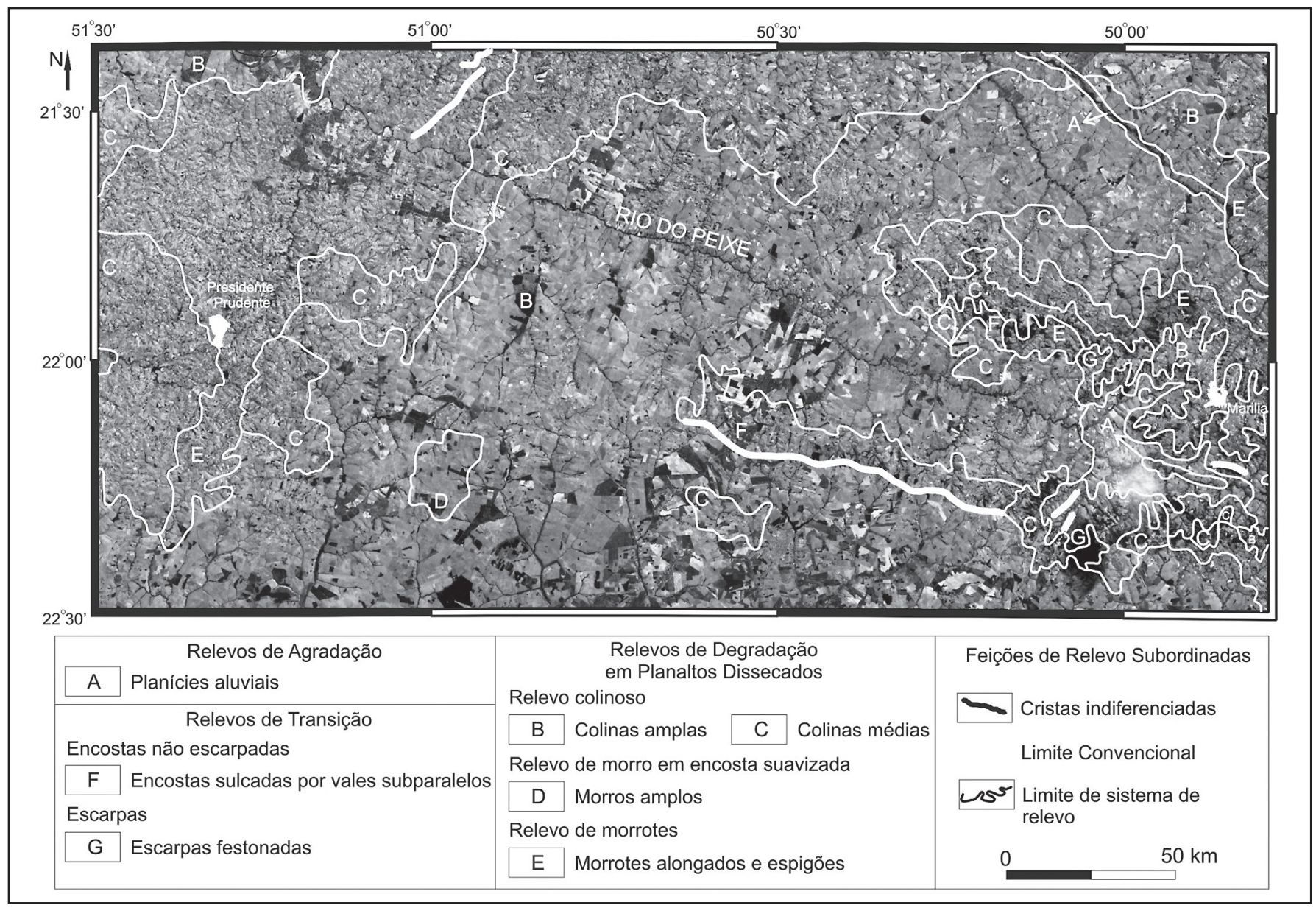

Figura 9 - Composição PC1 (componentes principais) da imagem de satélite LANDSAT-7 da área de estudo. Pode-se observar que na região da cidade de Marília ocorrem relevos cuestiformes, devido à ocorrência de rochas da Formação Marília, com alta densidade de drenagem associada as escarpas festonadas e morrotes alongados e espigões e onde a cobertura quaternária é mais espessa a densidade de drenagem é baixa. Notar o vale retilíneo do Rio do Peixe (unidades de relevo de Ponçano et al. 1981). 
sitos quaternários, detectados pelos estudos geomorfológicos regionais, são os seguintes:

a) As colinas amplas, que predominam na área de estudo, correspondem às ocorrências de depósitos colúvio-eluviais mais espessos. As granulometrias desses depósitos diferem dos que recobrem outras unidades geomorfológicas, pois são mais pobres em finos (silte e argila) e mais ricos em areia fina. Essas propriedades devem interferir nos valores de porosidade e permeabilidade, refletindo nas suas características geomorfológicas.

b) Quando as coberturas colúvio-eluviais tornam-se muito delgadas sobressaem as propriedades do substrato e, neste caso, os escoamentos superficiais são controlados pelas diferentes litologias do Grupo Bauru e pelas estruturas tectônicas presentes.

Sendo os depósitos de cobertura de origem predominantemente colúvio-eluvial, as suas datações correspodem às idades mínimas de peneplanização, que são as seguintes: I (1.000.000 a 400.000 anos A.P.), II (400.000 a 120.000 anos A.P.), III (120.000 a 10.000 anos A.P.) e IV (10.000 anos A.P. até hoje).

CONCLUSÕES Durante o Quaternário parecem ter ocorrido, na área de estudo, pulsos de erosão e sedimentação relacionados a possíveis mudanças paleoclimáticas e/ou neotectônicas. Esses fenômenos causaram mudanças de níveis de base, que introduziram transformações na geomorfologia.

A evolução geológica quaternária, da área de estudo, pode ser resumida pela seguinte seqüência de eventos:

a) Subseqüente ao término da sedimentação do Grupo Bauru no fim da Era Mesozóica teria ocorrido, segundo Riccomini (1997), intensa atividade deformadora da Bacia do Paraná. A julgar pela ausência de registro sedimentar do Paleógeno na área de estudo, segundo dados até agora disponíveis, sugere contínuo soerguimento com conseqüente remoção total de sedimentos deste período.

b) Conforme assertativas não-datadas de Stevaux (1993), o início de implementação da bacia hidrográfica do Rio Paraná teria se iniciado no Quaternário. Portanto, a idade TL de $980.000 \pm 100.000$ anos A.P. obtida neste trabalho, em depósitos colúvio-eluviais suprabasálticos nas adjacências da área de estudo (Ponto 50), parece corroborar a idéia daquele autor, porém maior número de datações é necessário.

c) Ainda, segundo Stevaux (1993) o paleoclima do início do Quaternário teria sido bem mais seco que hoje e este fato poderia ter favorecido a formação da superfície I (mais antiga) de aplainamento. Este fato teria também propiciado a intensa coluviação do manto de intemperismo previamente instalado sobre rochas sedimentares do Grupo Bauru.

d) Entre 1.000 .000 e 400.000 anos A.P. poderia ter ocorrido a instalação dos principais afluentes do Rio Paraná que, na área de estudo são representados pelos rios Paranapanema, do Peixe e Aguapeí. Neste intervalo de tempo a superfície I teria sido intensamente dissecada e reafeiçoada, mais ainda hoje se faz representar no Platô de Marília, que constitui morro-testemunho preservado da erosão segundo Suguio et. al. (1975), pela intensa cimentação carbonática.

e) Mudanças paleoclimáticas alargaram os vales e remodelaram o relevo, dando início à formação da superfície II. Entre 400.000 e 120.000 anos A.P. o Platô de Marília havia, provavelmente, adquirido a configuração semelhante à atual, tendo iniciado a formação da superfície III.

f) Entre 120.000 e 10.000 anos A.P. teria ocorrido a implantação definitiva da superfície III e no fim do Pleistoceno teria se iniciado a instalação da superfície IV, associada aos terraços dos rios do Peixe e Aguapeí, que continua até os dias atuais. Hoje em dia, o clima mais úmido e a eliminação da cobertura vegetal favorecem a erosão na área de estudo.

Agradecimentos À FAPESP pela concessão de Bolsa de Mestrado (Processo 00/10672-6) à Alethéa Ernandes Martins Sallun e Auxílio à Pesquisa (Processo 01/07469-7). Ao CNPq pela concessão de Auxílio à Pesquisa (Processo 47404/2001-9 NV).

\section{Referências}

Ab'Saber A.N. 1969. Os baixos chapadões do oeste paulista. Geomorfologia, 17:1-8.

Aitken M. J. 1985. Thermoluminescence dating. Academic, London, $359 \mathrm{pp}$.

Alexander T.L. \& Cady J.G. 1962. Genesis and hardening of laterite in soils. Washington D.C., United Sates Department of Agriculture, Technical Bulletin 1282, $90 \mathrm{p}$.

Almeida F.F.M. de. 1964. Geologia do Estado de São Paulo. IGG, 41:169-263.

Almeida F.F.M. de, Hasui H., Ponçano W.L., Dantas A.S.L., Carneiro C.D.R., Melo M.S. de, Bistrichi C.A. 1981. Mapa Geológico do Estado de São Paulo (escala 1:500.000). São Paulo, IPT, Publicação $\mathrm{n}^{\mathrm{o}} 1184$, v. $1,126 \mathrm{p}$.

Arid F.M. 1970 A Formação Bauru na região norte-ocidental do Estado de São Paulo. In: SBG, Cong. Bras. Geol., 24, Resumos das Conferências e Comunicações, p. 373-377.

Barcelos J.H. 1984. Reconstrução paleogeográfica da sedimentação do Grupo Bauru baseada na sua redefinição estratigráfica parcial em território paulista e no estudo preliminar fora do Estado de São Paulo. Tese de Livre Docência, Instituto de Geociências e Ciências Exatas, Universidade Estadual Paulista, 190 p.

Batezelli A. 2003. Análise da sedimentação cretácea no Triângulo Mineiro e sua correlação com áreas adjacentes. Tese de Doutoramento, Instituto de Geociências e Ciências Exatas, Universidade Esta- dual Paulista, 183 p.

Bigarella J.J. \& Andrade G.O. 1965. Contribution to the study of the Brazilian quaternary. In: H.E. Wright Jr. \& D.G. Frey (eds.) International studies on the Quaternary. Geol. Soc. Am., v. 84, p. 443-451 (special paper).

Bigarella J.J. \& Mousinho M.R. 1965. Considerações a respeito dos terraços fluviais, rampas de colúvio e várzeas. Bol. Paran. Geogr., 16/17:153-197.

Bourman R.P. 1993. Modes os ferricrete genesis: evidence from southeastern Australia. Zeits. Für Geom., 37:77-101.

Carvalho A. 1976. Solos da região de Marília: relações entre a pedogênese e a evolução do relevo. Tese de Doutoramento, Faculdade de Filosofia, Ciências e Letras, Universidade de São Paulo, São Paulo, $163 \mathrm{p}$.

Carver R.E. 1971. Procedures in Sedimentary Petrology. Wiley - Interscience, New York, 653 p.

Coimbra A.M. \& Fernandes L.A. 1994. A paleogeografia da Bacia Bauru (Cretáceo Superior, Brasil). In: Museo Paleontológico Egidio Feruglio, Cong. Arg. Paleo. Bioest., 6, Actas, p. 85-90.

Cruz O. 1974. A Serra do Mar e o litoral na área de Caraguatatuba. São Paulo. Instituto da Faculdade de Filosofia, Universidade de São Paulo. Série Teses e Monografias, v. 11, 181 p.

Etchebehere M.L. 2000. Terraços neoquaternários no Vale do Rio do Peixe, Planalto Ocidental Paulista: implicações estratigráficas e 
tectônicas. Tese de Doutoramento, Instituto de Geociências e Ciências Exatas, Universidade Estadual Paulista, 264 p.

Etchebehere M.L., Saad A.R., Fúlfaro V.J. 1999. Neotectônica no Vale do Rio do Peixe, SP - Evidências de deformação em sedimentos neocenozóicos. In: SBG, Simp. Geol. Sud., 6, Resumos, p. 94.

Fernandes L.A. 1992. A cobertura cretácica suprabasáltica no Paraná e Pontal do Paranapanema (SP): os Grupos Bauru e Caiuá. São Paulo. Dissertação de Mestrado, Instituto de Geociências, Universidade de São Paulo, São Paulo, 129 p

Fernandes L.A. 1998. Estratigrafia e evolução geológica da parte oriental da Bacia Bauru (Ks, Brasil). Tese de Doutoramento, Instituto de Geociências, Universidade de São Paulo, São Paulo, 232 p.

Fernandes L.A. \& Coimbra A.M. 1996. A Bacia Bauru (Cretáceo Superior, Brasil). An. Acad. Bras. Ciênc., 68:195-205.

Ferrari A.L., Riccomini C., Vasconcelos P. 2001. Ocorrência de rochas vulcânicas na porção central do Gráben de Guanabara (RJ) e suas implicações para a evolução do relevo no sudeste do Brasil. In: SBG, Simp. Geol. Sud., 7, Resumos, p.82.

Freitas R.O. 1951. Areias recentes da Praia Grande, SP. An. Acad. Bras. Ciênc., 23:163-175.

Freitas R.O. 1955. Sedimentação, estratigrafia e tectônica da Série Bauru (Estado de São Paulo). Bol. Fac. Fil. Ciênc. Let., 14(194):185.

Frye J.C. \& Willman H.B. 1962. Morphostratigraphic units and Pleistocene stratigraphy. Amer. Assoc. Petrol. Geolog. Bull., 60:777-786.

Fúlfaro V.J. \& Bjornberg A.J.S. 1994. Geologia. In: F.F. Falconi \& A Negro Júnior (eds.) Solos do litoral de São Paulo. Mesa Redonda, ABM/ASSECOB, pp.: 1-42.

Fúlfaro V.J. \& Suguio K. 1974. O cenozóico paulista: gênese e idade. In: SBG, Cong. Bras. Geol., 28, Anais, v. 3, p. 91-102.

Fúlfaro V.J., Saad S.R., Santos M.V., Vianna R.B. 1982. Compartimentação e evolução tectônica da Bacia do Paraná. Rev. Bras. Geoc., 12:590-611.

Giannini P.C.F. 1987. Sedimentação quaternária na planície costeira de Peruibe-Itanhaém (SP). Dissertação de Mestrado, Instituto de Geociências, Universidade de São Paulo, S. Paulo, 234 p.

King L.C. 1956. A geomorfologia do Brasil oriental. Rev. Bras. Geog. 2:3-48.

Lepsch I.F. 1977. Superfícies geomorfológicas e depósitos cenozóicos em Echaporã, SP. Bol. Paul. Geogr., 53:5-34.

Martin L. \& Suguio K. 1975. The State of São Paulo coastal marine Quaternary geology - The ancient strandlines. An. Acad. Bras. Ciênc., 47:249-263.

Massad F. 1994. Propriedades dos sedimentos marinhos. In: F.F. Falconi \& A. Negro Júnior (eds.) Solos do litoral de São Paulo. Mesa Redonda, ABM/ASSECOB, pp.: 99-128.

Massoli M. 1980. Geologia da Folha Santa Rita do Passa Quatro. Rev. Inst. Geol., 1(1):7-14.

Meis M.R.M. \& Moura J.R.S. 1984. Upper Quaternary sedimentation and hillslope evolution: Southeastern Brazilian Plateau. Amer. Jour. Scie., 284:132-151.

Melo M.S. de \& Ponçano W.L. 1983. Gênese, distribuição e estratigrafia dos depósitos cenozóicos no Estado de São Paulo. São Paulo, IPT, Série Monografias no 1394, 75 p.

Melo M.S., Coimbra A.M., Cuchierato G. 1997. Fácies sedimentares da Formação Rio Claro, Neocenozóico da Depressão Periférica Paulista. Rev. Inst. Geol., 18(1/2):49-63.

Melo M.S., Coimbra A.M., Cuchierato G. 2001. Gênesis of Quaternary sedimentary covers in Southeastern Brazil. Quatern., 12:179-188.

Melo M.S., Fernandes L.A., Moraes M.C., Coimbra A.M. 1994. Níveis de terraços fluviais do baixo Ribeira do Iguape (SP): a Formação Eldorado. An. Acad. Bras. Ciênc., 66(3):319-330.

Milani E.J. 1997. Evolução tectono-estratigráfica da Bacia do Paraná e seu relacionamento com a geodinâmica fanerozóica do Gondwana sul-ocidental. Tese de Doutoramento, Instituto de Geociências, Universidade Federal do Rio Grande do Sul, Porto Alelgre, 255 p.

Milani E.J. \& Ramos V.A. 1998. Orogenias paleozóicas do domínio sul-oriental do Gondwana e os ciclos de subsidência da Bacia do Paraná. Rev. Bras. Geoc., 28(4):473-484.

Parfenoff A., Pomerol C., Tornenq J. 1970. Le minéraux em grains. Masson et Cie, Paris, $580 \mathrm{p}$.

Penteado M.M. \& Ranzani G. 1973. Problemas geomorfológicos relacionados a gênese dos solos podzolizados. Sedim. Ped., 6:1-23.
Ponçano W.L., Carneiro C.D.R., Bistrichi C.A., Almeida F.F.M.de, Prandini F.L. 1981. Mapa Geomorfológico do Estado de São Paulo. São Paulo, IPT, Publicação no. 1183, vol. I., 94 p.

Queiroz Neto J.P. \& Jounaux A. 1978. Carta geomorfológica do Vale do Rio do Peixe em Marília, SP. Sedim. Ped., 10:1-20.

Queiroz Neto J.P., Jounaux A., Pellerin J., Carvalho A. 1977. Formações superficiais da região de Marília, SP. Sedim. Ped., 31:1-28.

Rego L.F.M. 1946. Notas sobre a geomorfologia de São Paulo e sua gênese. Bol. Geogr., 37:9-17.

Renne P., Ernesto M., Pacca I.G., Coe R.S., Glen J.M., Prévot M., Perrin M. 1992. The age of Paraná Flood Volcanism, rifting of Gondwanaland, and the Jurassic-Cretaceous boundary. Science, 258:975-979.

Riccomini C. 1995. Tectonismo gerador e deformador dos depósitos pós-gondvânicos da porção centro-oriental do Estado de São Paulo e áreas vizinhas. Tese de Livre-Docência, Instituto de Geociências, Universidade de São Paulo, São Paulo, 100 p.

Riccomini C. 1997. Arcabouço estrutural e aspectos do tectonismo gerador e deformador da Bacia Bauru no Estado de São Paulo. Rev. Bras. Geoc., 27(2):153-162.

Sallun A.E.M. 2003. Depósitos cenozóicos da região entre Marília e Presidente Prudente (SP). Dissertação de Mestrado, Instituto de Geociências, Universidade de São Paulo, 171 p.

Sallun A.E.M., Suguio K., Tatumi S.H., Yee M. 2006. Dosimetria da radiação cósmica por espectroscopia-gama e datação de depósitos cenozóicos da porção central da Bacia Hidrográfica do Rio Paraná (MS, PR e SP). In: SBG, Cong. Bras. Geol., 43, Resumos Expandidos, CD-ROM.

Silveira J.D. 1950. Baixadas litorâneas quentes e úmidas. Tese Provimento de Cátedra de Geografia Física, Faculdade de Filosofia, Ciências e Letras, Universidade de São Paulo, S. Paulo, 224 p.

Souza C.R. de G. 1997. As células de deriva litorânea e a erosão nas praias do estado de São Paulo. Tese de Doutoramento, Instituto de Geociências, Universidade de São Paulo, S. Paulo, 2v.

Stevaux J.C. 1993. O Rio Paraná: geomorfogênese, sedimentação e evolução quaternária de seu curso superior (região de Porto Rico, $P R$ ). Tese de Doutoramento, Instituto de Geociências, Universidade de São Paulo, S. Paulo, 242 p.

Suarez J.M. 1976. Contribuição à geologia do extremo oeste do estado de São Paulo - parte 2. Bol. Geog., 34(248):119-1555.

Suarez J.M. 1991. A localização das cidades no extremo oeste do Estado de São Paulo (Brasil) e seus problemas. In: Enc. de Geog. Am. Lat., 3, Memória, v. 4, p.323-336.

Suguio K. 1973. Formação Bauru: calcários e sedimentos detríticos associados. Tese de Livre-Docência, Instituto de Geociências, Universidade de São Paulo, S. Paulo, 2 v.

Suguio K. 1980. Fatores paleoambientes e paleoclimáticos e subdivisão estratigráfica do Grupo Bauru. In: SBG/Núcleo SP, A Formação Bauru no Estado de São Paulo e Regiões Adjacentes, 7, Coletânea de trabalhos e debates, p.15-26.

Suguio K. \& Coimbra A.M. 1976. Estudo sedimentológico das "bandas onduladas" de solos da Formação Bauru na área balizada pelas cidades de Osvaldo Cruz - Rancharia e Tupã, Estado de São Paulo. Bol. IGG, 7:27-38.

Suguio K. \& Petri S. 1973. Stratigraphy of the Iguape-Cananéia lagoonal region sedimentary deposits, São Paulo State, Brazil, Part I: Field observations and grains size analysis. Bol. IG, 4:1-20.

Suguio K., Berenholc M., Salati E. 1975. Composição química e isotópica dos calcários e ambientes de sedimentação da Formação Bauru. Bol. $I G, 6: 55-75$.

Wentworth C.K. 1922. A scale of grade and class terms for clastic sediments. Jour. of Sedim. Petrol., 30:377-392.

Wintle A. G. \& Huntley D. J. 1980. Thermoluminescence dating of ocean sediments. Canad. Jour. Eart. Scienc., 17:348-360.

Zálan P.V., Wolff S., Conceição J.C.J., Marques A., Astolfi M.A.M., Vieira S.I., Appi T.V., Zanoto A.O. 1990. Bacia do Paraná. In: R.Gabaglia \& E.J. Milani (eds.) Origem e Evolução de Bacias Sedimentares. Petrobrás, pp.: 135-138.

Manuscrito A1490 Aprovado em 13 de setembro de 2006 